Please do not remove this page

RMIT

UNIVERSITY

\title{
Hanging off a bar
}

Mueller, Florian Floyd; Toprak, Cagdas; Graether, E; Walmink, W; Bongers, Bert; van den Hoven, E https://researchrepository.rmit.edu.au/esploro/outputs/9921858685901341/filesAndLinks?institution=61RMIT_INST\&index=null

Mueller, F. F., Toprak, C., Graether, E., Walmink, W., Bongers, B., \& van den Hoven, E. (2012). Hanging off a bar. CHI '12 Extended Abstracts on Human Factors in Computing Systems, 1055-1058.

https://doi.org/10.1145/2212776.2212384

Document Version: Accepted Manuscript

Published Version: https://doi.org/10.1145/2212776.2212384

Repository homepage: https://researchrepository.rmit.edu.au (C) 2012 The authors

Downloaded On 2023/04/26 22:25:55 +1000

Please do not remove this page 
Thank you for downloading this document from the RMIT Research Repository.

The RMIT Research Repository is an open access database showcasing the research outputs of RMIT University researchers.

RMIT Research Repository: http://researchbank.rmit.edu.au/

\section{Citation:}

Mueller, F, Toprak, C, Graether, E, Walmink, W, Bongers, B and van den Hoven, E 2012, 'Hanging off a bar', in Joseph A. Konstan (ed.) CHI '12 Extended Abstracts on Human Factors in Computing Systems, United States, 05 -10 May 2012, pp. 1055-1058.

See this record in the RMIT Research Repository at: https://researchbank.rmit.edu.au/view/rmit:15727

Version: Accepted Manuscript

Copyright Statement: (c) 2012 The authors

Link to Published Version:

http://dx.doi.org/10.1145/2212776.2212384 
(c) 2012 The authors. This is the authors' version of the work. It is posted here for your personal use. Not for redistribution. The definitive Version of Record was published in CHI '12 Extended Abstracts on Human Factors in Computing Systems, http://dx.doi.org/10.1145/2212776.2212384. 


\section{Hanging off a Bar}

\begin{tabular}{|c|c|}
\hline Florian 'Floyd' Mueller & Wouter Walmink \\
\hline Exertion Games Lab & Exertion Games Lab \\
\hline RMIT University & RMIT University \\
\hline $\begin{array}{l}\text { Melbourne, Australia } \\
\text { floyd@exertiongameslab.org }\end{array}$ & $\begin{array}{l}\text { Melbourne, Australia } \\
\text { wouter@exertiongamesla }\end{array}$ \\
\hline Cagdas 'Chad' Toprak & Bert Bongers \\
\hline Exertion Games Lab & Interactivation Studio \\
\hline RMIT University & UTS School of Design \\
\hline $\begin{array}{l}\text { Melbourne, Australia } \\
\text { chad@exertiongameslab.org }\end{array}$ & $\begin{array}{l}\text { Sydney, Australia } \\
\text { bertbon@xs4all.nl }\end{array}$ \\
\hline Eberhard Graether & Elise van den Hoven \\
\hline Exertion Games Lab & Eindhoven University of \\
\hline RMIT University & Technology \\
\hline Melbourne, Australia & the Netherlands \\
\hline
\end{tabular}

Copyright is held by the author/owner(s)

CHI'12, May 5-10, 2012, Austin, Texas, USA.

ACM 978-1-4503-1016-1/12/05.

\begin{abstract}
Exertion Games involve physical effort and as a result can facilitate physical health benefits. We present Hanging off a Bar, an action hero-inspired Exertion

Game in which players hang off an exercise bar over a virtual river for as long as possible. Initial observations from three events with audiences ranging from the general public to expert game designers suggest that Hanging off a Bar can be engaging for players and facilitate intense exertion within seconds. Furthermore, we collected suggestions for what game elements players believe could entice them to increase their physical effort investment. These suggestions, combined with Hanging off a Bar as research vehicle due to the easy measurement of exertion through hanging time, enable future explorations into the relationship between digital game elements and physical exertion, guiding designers on how to support exertion in digital games.
\end{abstract}

\section{Keywords}

Exertion games; exertion interfaces; whole-body

interaction; exergames; sport; game design 


\section{ACM Classification Keywords}

H.5.2. [Information Interfaces and Presentation]: User Interfaces - Miscellaneous.

\section{General Terms}

Design, Human Factors

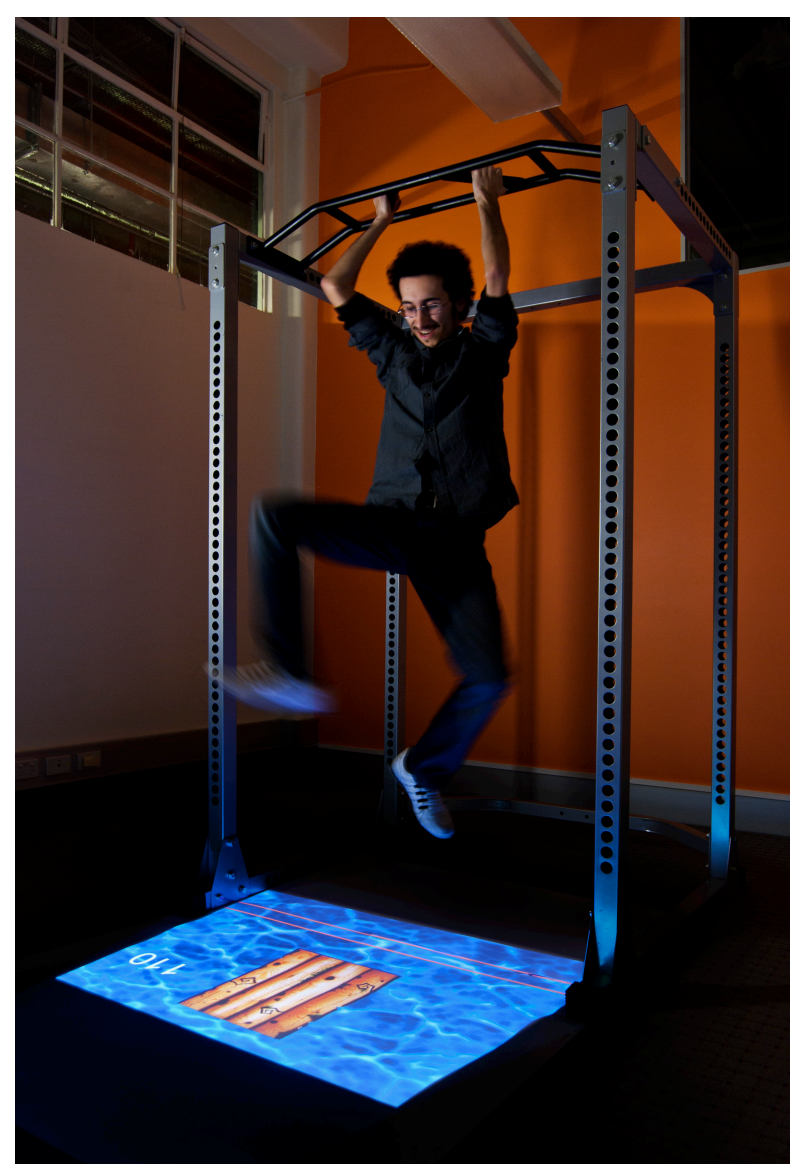

Figure 1. Hanging off a Bar.

\section{Introduction}

Exertion Games are digital games where the outcome of the game is significantly informed by physical effort [4]. The most prominent exertion game systems today are consoles such as Microsoft's Xbox Kinect,

Nintendo's Wii and Sony's Playstation Move. Although they are believed to provide physical health benefits

[3], they have been criticized for promoting only limited physical effort investment, especially when compared to existing sports activities [2]. One reason for this could be that the sensors involved mainly aim to capture flailing of body limbs as generic input, rather than focusing on specific exertion actions. In contrast to this, we present Hanging off a Bar, an exertion game that aims to facilitate intense exertion.

\section{Hanging off a Bar}

Hanging off a Bar emerged from our teachings on Exertion Games [5]. One of its aims is to challenge our understanding that Exertion Games necessarily require bodily movements: Hanging off a Bar is aimed to be intensely exhausting, yet users do not move much. The game plays with an action hero theme, inspired by narratives where the protagonist hangs onto something over a river or similar, demonstrating that hanging with pure handgrip strength can be very tiring and is not as easy as most movies make it appear.

In Hanging off a Bar, the player grabs onto an iron bar and begins hanging freely. A pressure mat underneath the bar interprets the hanging to start the game and a counter projected onto the floor displays the time hung (Fig. 1). The projection also includes a digital river, motivating the player to keep on hanging. After 10 seconds, a virtual raft floats down the river. Once the raft arrives under the feet of the player, the player can 
let go of the bar and jump "onto" the raft, allowing some recovery time for the arms and hands. However, the raft continues to float down the river, and so the player must grab the bar again. Over time the rafts get shorter and the gap between each raft longer. The goal is to hang on for as long as possible.

Most closely related to our work are the yoga-inspired instruction sets that use the Nintendo Wii Balance Board [6] as they also focus on particular body poses that facilitate exertion. However, our approach is a game rather than an instructor-based system. In consequence, we see this as an opportunity to use Hanging off a Bar as a research vehicle to explore the relationship between digital game elements and exertion. We present preliminary observations from the general public and expert game designers playing the game as well as report their suggestions on which digital game elements they believe could entice them to invest increased physical effort in order to fuel such explorations.

\section{Observations of playing Hanging off a Bar}

We report on initial observations from three separate events where we exhibited Hanging off a Bar. The first event coincided with an art gallery's open reception, attracting people interested in interactive art. Our second event was in our lab, where we hosted the International Game Developers Association's local chapter meet, which attracted over 100 expert game designers. Our third event was in a public shopping mall, where the game was accessible to the general public as part of a digital festival. Preliminary feedback from these events suggests that players found the experience engaging despite the physical effort involved, as participants were eager to play.
Participants learned quickly from watching others play the game, suggesting that Hanging off a Bar was easy to engage with. The game was also sufficiently challenging as intended: although fit players such as rock-climbers achieved scores of over 2 minutes,

typical hanging times were under a minute, while some finished in less than ten seconds.

\section{Suggestions to entice exertion}

Hanging off a Bar allows the easy measurement of participants' effort investment through the logging of hanging times. Furthermore, the specific software implementation allows for the easy modification of the digital game elements. These features make Hanging off a Bar a convenient research vehicle for planned future work where we aim to explore the relationship between game elements and exertion. In order to fuel this exploration, we now present suggestions players had in terms of which game elements they thought could entice them to increase their physical effort investment.

Better graphics

A number of the game designers saw opportunities to improve the graphics towards photorealism, proposing that increased visual fidelity could facilitate increased physical effort investment.

Facilitating fearful emotions

Hanging off a Bar plays with the idea of dropping into a river, fostering fearful emotions. It was suggested that we play with these emotions through additional game elements, such as virtual crocodiles or fire, in order to entice more effort investment. 
Hanging together

Although Hanging off a Bar currently supports only one player at a time, we often saw bystanders cheering a player on, turning it into a social experience. Software modifications could also allow bystanders to trigger the appearance of rafts upon seeing players getting tired. Hanging socially might encourage increased effort, in line with social facilitation theory that suggests that the presence of others can influence performance [7].

\section{Virtual audience}

Another avenue to socially extend the game could be to include a virtual audience. Further investigation could examine if a player's exertion changed depending on if the audience is controlled by software or by humans. For example, the virtual audience could be controlled by the player's friends who submit cheers through a website, similar to the Facebook chants enabled in the Nike+ jogging app [1].

\section{Conclusion}

We have presented Hanging off a Bar, an Exertion Game that leverages intense physical effort over a very short time. Initial observations with a wide range of users suggest that the game can be engaging. The simple exertion activity of hanging allows using Hanging off a Bar as a convenient research vehicle to explore the relationship between exertion and game elements. To inform this exploration, we have asked players what they think would entice them to invest increased physical effort, and the themes of better graphics, facilitating fearful emotions, hanging together and virtual audience emerged. Future work will show if and by how much these elements can increase player exertion. Eventually, Hanging off a Bar will help to develop strategies for the design of future exertion games, ultimately resulting in better exertion games, helping players to profit from the many benefits of exertion.

\section{Acknowledgements}

We like to thank the team around Luke Sayers, Jack Crosby, Josh Tatangelo and Lauren Rashleigh for originally suggesting the idea and Andrew Lewis and Kyhil Duggan for supporting this project.

\section{References}

[1] Apple Nike + iPod, http://www.apple.com/ipod/nike.

[2] Graves, L., Ridgers, N. and Stratton, G. The contribution of upper limb and total body movement to adolescents' energy expenditure whilst playing Nintendo Wii. European Journal of Applied Physiology, 104 (4). (2008), 617-623.

[3] Guy, S., Ratzki-Leewing, A. and Gwadry-Sridhar, F. Moving Beyond the Stigma: Systematic Review of Video Games and Their Potential to Combat Obesity. (2011).

[4] Mueller, F., Agamanolis, S. and Picard, R., Exertion Interfaces: Sports over a Distance for Social Bonding and Fun. CHI '03, 561-568.

[5] Mueller, F., Edge, D., Vetere, F., Gibbs, M.R.,

Agamanolis, S., Bongers, B. and Sheridan, J.G., Designing Sports: A Framework for Exertion Games. CHI '11, 26512660.

[6] Nintendo. Wii Balance Board, 2009.

http://www.nintendo.com/wii/console/accessories/balance board.

[7] Weinberg, R.S. and Gould, D. Foundations of Sport and Exercise Psychology. Human Kinetics, Champaign, IL, USA, 2006. 